\title{
Failure of the human rectum to absorb electrolytes and water ${ }^{1}$
}

\author{
GHISLAIN J. DEVROEDE AND SIDNEY F. PHILLIPS \\ From the Gastroenterology Unit, Mayo Clinic and Mayo Foundation, Rochester, Minnesota
}

SUMMARY Absorption of electrolytes and water from the human rectum was quantified by sequential sampling of physiological solutions instilled into the rectum and by the method of continuous intraluminal perfusion. The absorptive function of the rectum measured by the perfusion technique was also compared with that of the entire large intestine. The rectum did not absorb sodium, chloride, or water from isotonic solutions, even after 90 minutes of exposure. The remainder of the colon effectively absorbed sodium, chloride, and water at a rate of approximately $1 \%$ of the infused load per minute of contact between perfusates and mucosa.

It is not known whether electrolytes and water are absorbed at equal rates from all segments of the large intestine although the existence of regional variations in colonic function would have relevance to the pathology of partial resection of the colon or segmental colonic disease (Phillips, 1969). When the human colon and rectum are perfused simultaneously, the proximal colon is thought to contribute more to salt and water absorption than the distal colon and rectum (Levitan, Fordtran, Burrows, and Ingelfinger, 1962). We are unaware of studies which directly compare absorption from the intact human rectum with absorption from other areas of the large intestine. Electrolytes and water were not absorbed when isotonic solutions were instilled into two surgically isolated loops of human rectum (Annis and Alexander, 1952; Duthie and Atwell, 1963). Certain drugs (Levitan, Bikerman, Burrows, and Ingelfinger, 1963) and tritiated water (Levitan and Brudno, 1967) are absorbed across the rectosigmoid in health or when ulcerative proctosigmoiditis is present, but a comparison with the remaining colon was not made.

In the present studies, we quantified and compared electrolyte and water absorption from

${ }^{1}$ This investigation was supported in part by Research Grant AM-6908 from the National Institutes of Health, Public Health Service. the rectum and the entire large intestine in inan. Sodium, chloride, and water were not absorbed from the rectum, contrasting markedly with their effective absorption from other regions of the $\exists$ large intestine.

\section{Material and Methods}

In five studies on three healthy male volunteers, $\mathscr{\sigma}$ aged 25 to 35 years, $100 \mathrm{ml}$ of a test solution was $\tilde{O}$ instilled into the rectum and serial samples were ${ }_{\mathrm{C}}^{N}$ removed during the following 90 minutes (Figure 1). A Miller-Abbott tube, modified by the addition of a small-bore $(1 \cdot 2 \mathrm{~mm})$ poly- $\widetilde{\Phi}$ ethylene tube, was inserted into the uncleansed $\stackrel{?}{?}$ rectum until the caudad end of the latex balloon 0 was $15 \mathrm{~cm}$ from the dentate line. The position of the tube was checked fluoroscopically. The balloon was then inflated with $240 \mathrm{ml}$ of water $\stackrel{\mathbb{Q}}{\Omega}$ and gentle continuous suction was applied orado to the balloon. Throughout the study, subjects remained recumbent on the right side. The testo solution was isotonic (285 to $290 \mathrm{mOsm} / 1$, pH $8 \cdot 0,37^{\circ} \mathrm{C}$ ), designed to simulate ileostomy discharge (Kanaghinis, Lubran, and Coghill, 1963), and contained (in m-equiv/l) sodium 130, potassium 24 , chloride 100 , and bicarbonate 54 , and also $0.1 \%$ glucose, $0.5 \%$ polyethylene glycol 


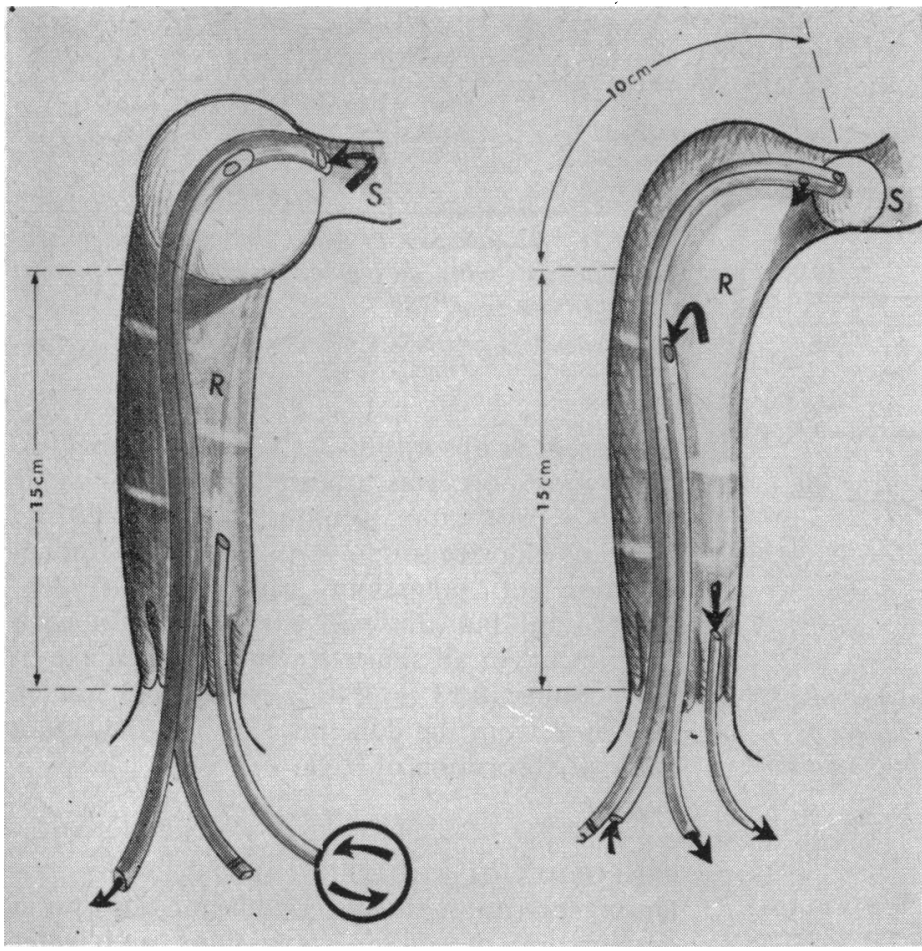

Fig. 1 Techniques for study of rectal absorption of water and electrolytes. Left, bolus studies: modified Miller-Abbott tube for partial occlusion of rectosigmoid junction with orad suction (S). Solutions were introduced and sampled from rectum (R) through adjacent single-lumen tube. Right, perfusion studies: three-lumen tube for inflation of nonocclusive balloon, introduction of samples at $25 \mathrm{~cm}$, and sampling at $15 \mathrm{~cm}$ from dentate line; solutions drained by additionai tube at dentate line.

(PEG) $^{1}$ as a nonabsorbable marker, and $2 \mu \mathrm{c}$ of ${ }^{24}$ sodium. After the subject had accommodated to the distension caused by the balloon, as indicated by lack of rectal discomfort, the solution was introduced caudad to the balloon, through the small tube. Thereafter, $3 \mathrm{ml}$ of rectal contents was removed each 10 minutes for 90 minutes. Leakage from the anus was quantified by liquid so lost being absorbed onto gauze placed around the anal margin. The swab was rinsed in a known volume of water, the rinse analysed for PEG, and the results were corrected appropriately.

To extend these observations and to avoid the unpredictable effect of a large distending balloon in the rectum, seven additional studies were performed on four healthy male volunteers (aged 25 to 50 years) utilizing the technique of constant perfusion of the rectum (Figure 1). Subjects were prepared with an enema of $0.9 \%$ solution of sodium chloride one hour before the study. A composite three-lumen polyvinyl tube (outside diameter of each tube $0.8 \mathrm{~mm}$ ), incorporating a non-occlusive terminal balloon, was introduced through a proctoscope until the balloon was $25 \mathrm{~cm}$ orad to the dentate line. The balloon was inflated with $25 \mathrm{ml}$ of water and the test solutions were infused $^{2}$ at a constant rate $(5 \mathrm{ml} / \mathrm{min})$ immediately caudad to the balloon. Perfusates were sampled by siphonage $10 \mathrm{~cm}$ distal to their site of infusion and again at the dentate line. Absorption from the $15-\mathrm{cm}$ rectal segment was calculated, by standard formulas (Levitan et al, 1962), from the changes in concentration of electrolytes and PEG between the proximal and the distal site of sampling. Samples from both sites were pooled in 30minute collections for a total of 90 minutes. The solutions, either $154 \mathrm{mM}$ sodium chloride or the simulated ileostomy fluid, contained $0.1 \%$ glucose, $0.5 \%$ PEG, and $10 \mu \mathrm{c}$ of ${ }^{24} \mathrm{Na}$ per litre. In two studies, the distal sampling site was occluded for 15 minutes to prolong the time of contact between perfusing solutions and the rectal mucosa.

Absorption from the entire large intestine was measured in four healthy male subjects (aged 21 to 50 years) by a modification of the colonic perfusion technique described previously (Levitan et al, 1962; Devroede and Phillips, 1969a). In brief, a composite four-lumen tube was passed by mouth until the terminal orifice was in the caecum. After thorough cleansing of the colon, perfusing solutions of $154 \mathrm{mM}$ sodium chloride, $0.1 \%$ glucose, and $0.5 \%$ PEG were infused into the caecum at 5,10 , and $16 \mathrm{ml} / \mathrm{min}$, collected from a rectal tube, and monitored for the development of 'steady state' conditions (Devroede and Phillips, 1969a). When the steady state was achieved, perfusion was interrupted for 60 seconds, $10 \mathrm{mg}$ of a second poorly ahsorbed marker, phenolsulfonphthalein (PSP), was injected into the caecum, and perfusion was reestablished for a further 60 to 120 minutes. Recovery of PSP at the rectum allowed the construction of 'dye-dilution curves' from which mean transit times of perfusates through the colon were calculated (Devroede and Phillips, 1969a). Net colonic absorption of electrolytes and water, relative to PEG, was computed from standard formulas (Levitan et al, 1962) on rectal samples collected and analysed for six sequential 10-minute periods during the steady state. The rates of infusion were performed in tandom order on individual subjects.

\section{ANALYTICAL METHODS}

Sodium and potassium were measured with a flame photometer ${ }^{3}$ and chloride electrotitrimetrically ${ }^{4}$. Concentrations of PSP were read at $560 \mathrm{~m} \mu$, PEG at $650 \mathrm{~m} \mu$ (Hyden, 1956), and ${ }^{24} \mathrm{Na}$ was counted twice for 400 seconds $^{5}$.

${ }^{1}$ Carbowax, M.W. 4000, Union Carbide, New York, N.Y. 'Beckman infusion pump, model 746, Beckman Instruments, Fullerton, California.

'Instrumentation Laboratory, Lexington, Massachusetts. 'Chloridometer, Buchler Instruments, Fort Lee, N.J.

'Sodium iodide well, dual channel analyzer 600-059, Picker $\boldsymbol{X}$-Ray Corporation, White Plains, N.Y. 


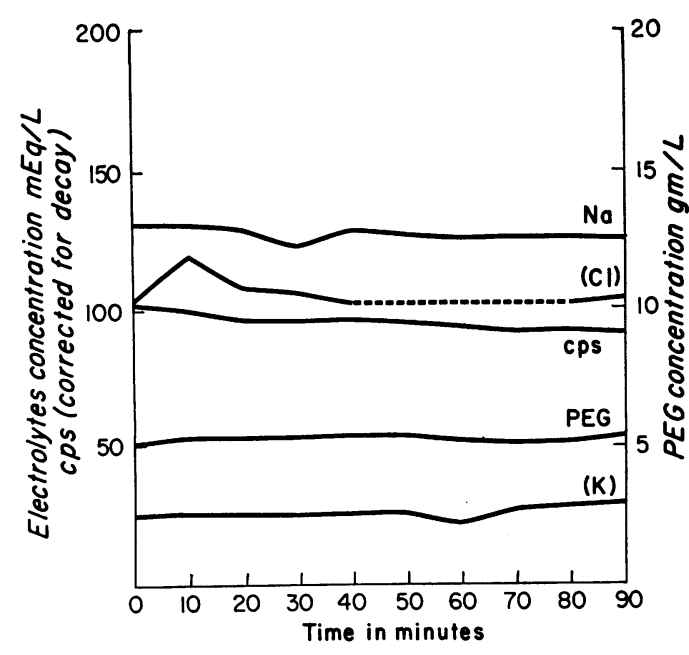

Fig. 2 Concentrations of PEG, electrolytes, and ${ }^{24} \mathrm{Na}$ (counts per second) in sequential samples of isotonic electrolyte solution remaining in the human rectum for 90 minutes.

\section{ANALYSIS OF RESULTS}

In the bolus studies, results have been expressed as a percentage of the initial test solution absorbed from the rectum each minute. The results of perfusion experiments, in both the rectum and the colon, are expressed as microequivalents of electrolyte or millilitres of water absorbed by the test segment per minute of perfusion. In addition, absorption during colonic perfusion was corrected for transit time of perfusates through the colon at different rates of infusion. Absorption from the colon was thereby expressed relative to the duration of contact between perfusing solutions and the absorptive surface. The calculation applied was Ap $=\frac{\text { At } \times 100}{\text { Ain } \times \text { TT }}$, where Ap is the percentage of contents absorbed per minute of transit time through the colon. At the total amount (ml or $\mu$-equiv) absorbed per minute of perfusion, Ain the amount ( $\mathrm{ml}$ or $\mu$-equiv) infused per minute into the caecum, and TT the transit time (minutes) obtained from planimetry of the dye-dilution curve (Devroede and Phillips, 1969a).

\section{Results}

\section{BOLUS STUDIES}

Electrolytes and water were never absorbed from the rectum even after the test solution was exposed to the mucosa for 90 minutes. This is illustrated by the persistence of initial concentrations of electrolytes and PEG in one subject (Fig. 2) as was found in all other studies. The $95 \%$ confidence intervals of the means of five studies always included zero net transport.

\begin{tabular}{lcc}
\hline & $\begin{array}{c}\text { Sodium Chloride } \\
\text { Solution }(n=3)^{1}\end{array}$ & $\begin{array}{l}\text { Ileostomy Solution } \\
(n=4)^{1}\end{array}$ \\
\hline Water & $+0.02 \pm 0.06$ & $+0.05 \pm 0.06$ \\
Sodium & $+0 \pm 23$ & $+6 \pm 10$ \\
Chloride & $-14 \pm 8$ & $+10 \pm 5$ \\
Potassium & $+3 \pm 3$ & $+2 \pm 2$ \\
\hline
\end{tabular}

Table I Net transport of water $(\mathrm{ml} / \mathrm{min})$ and electrolytes ( $\mu$-equiv/min) during perfusion of the human $\mathbb{\otimes}$ rectum (mean $\pm S E M)$

${ }^{1}$ A plus sign (+) preceding a mean value signifies absorption; a minus sign $(-)$ secretion.

Expressed as absorption (+) or secretion (-), rectal transport was (mean \pm SEM): water $-0 \cdot 16 \pm 0 \cdot 10 \% / \mathrm{min} ;$ sodium $-0.05 \pm 0.07 \%$ min; and chloride $-0.02 \pm 0.10 \% / \mathrm{min}$. Minimal ir secretion of potassium occurred $\left(-0.36 \pm \frac{\vec{\omega}}{\omega}\right.$ $0.09 \% / \mathrm{min}$ ) but this was not verified in each $\infty$

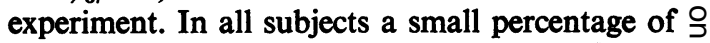
${ }^{24} \mathrm{Na}$ counts $(0.13 \pm 0.03 \% / \mathrm{min})$ could not be recovered from the contents (Fig. 2), indicating minimal absorption of ${ }^{24} \mathrm{Na}$.

\section{PERFUSION OF THE RECTUM}

During perfusion studies, significant absorption or secretion of sodium, potassium, and water was never demonstrated (Table I). The net transport measured was trivial since confidence $\mathbb{D}$ limits of the mean results for sodium, potassium, and water included zero net transport $(P<0.05)$. When the collection tube was clamped, allowing the test solution to remain in the rectum for an additional 15 minutes, one subject secreted small amounts of chloride into sodium chloride solution and absorbed small amounts of chloride from the ileostomy solution. In all other subjects, chloride transport was near zero. Clamping of the distal sampling site did not influence absorption in other ways.

\section{PERFUSION OF THE ENTIRE COLON}

Sodium, chloride, and water were always absorbed when infused at each rate, and absolute ${ }_{N}$ quantities absorbed increased with faster rates $\mathrm{C}$ of infusion (Figure 3). Mean transit time of perfusates through the colon was inversely related to the speed of infusion (Figure 4). When absorption of electrolytes and water at each infusion rate was corrected for transit time through the colon, the parameter of colonic $\overrightarrow{\mathbb{D}}$ absorption thus obtained was relatively constant. $\frac{\mathbb{D}}{\mathbb{D}}$ Absolute amounts of electrolytes and water $\bigcirc$ absorbed were least during infusion at $5 \mathrm{ml} / \mathrm{min}$, but the percentage of infusate absorbed was o highest; however, colonic transit time was also greatest at this speed (Table II). At faster rates of infusion, absolute absorption increased but, since $\rightleftharpoons$ the infused load also increased, the percentage absorption decreased and colonic transit time declined simultaneously (Table II). The mean percentage of infused load absorbed per minute 


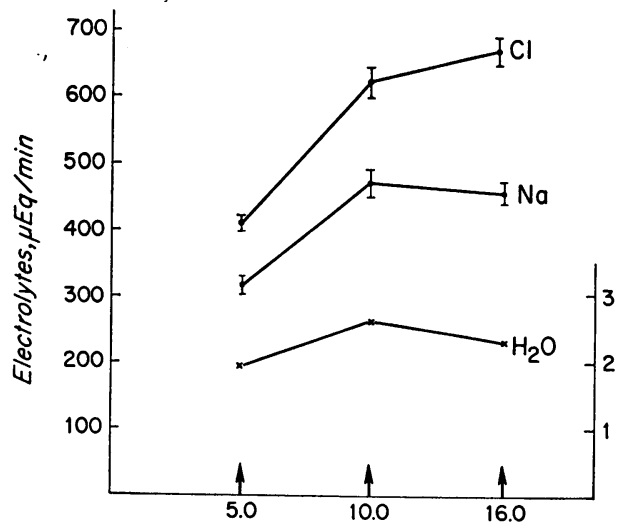

Rate of infusion, $\mathrm{ml} / \mathrm{min}$

Fig. 3 Absorption of sodium, chloride, and water from human colon at different rates of perfusion, mean $\pm S E M$ (not shown for water as SEM too small for illustration), $n=4$.

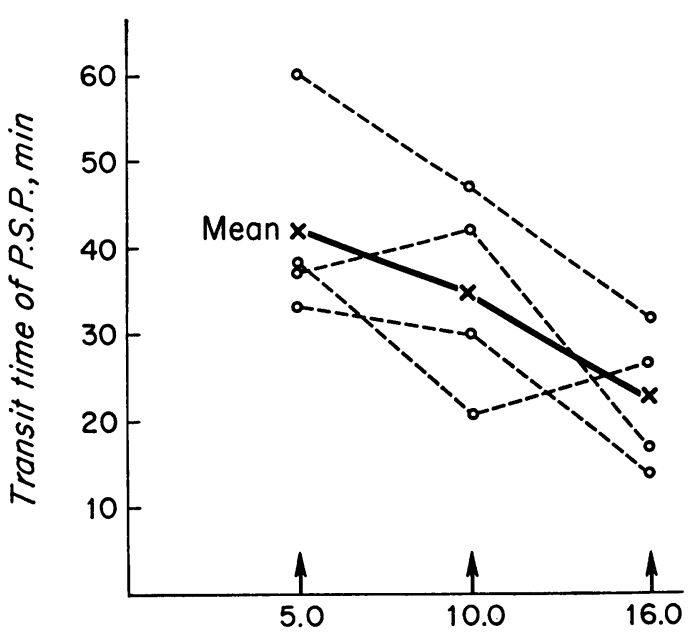

Rate of infusion $\left(\mathrm{ml} / \mathrm{min}^{-1}\right)$

Fig. 4 Effect of infusion rate on mean transit time of PSP through human colon. Interrupted lines join symbols representing studies in the same patient.

\begin{tabular}{|c|c|c|c|c|c|c|}
\hline \multirow{2}{*}{$\begin{array}{l}\text { Mean } \\
\text { Transit } \\
\text { Time of } \\
P S P \text { (min) }\end{array}$} & \multicolumn{3}{|c|}{ Water (ml/min) } & \multicolumn{3}{|c|}{ Sodium ( $\mu$-equiv/min) } \\
\hline & $\begin{array}{l}\text { Infusion } \\
\text { Rate }\end{array}$ & $\begin{array}{l}\text { Absorption } \\
\text { Rate }\end{array}$ & $\begin{array}{l}\text { Percentage } \\
\text { Absorption }\end{array}$ & $\begin{array}{l}\text { Infusion } \\
\text { Rate }\end{array}$ & $\begin{array}{l}\text { Absorption } \\
\text { Rate }\end{array}$ & $\begin{array}{l}\text { Percentage } \\
\text { Absorption }\end{array}$ \\
\hline $\begin{array}{l}43 \\
35 \\
24\end{array}$ & $\begin{array}{r}5 \\
10 \\
16\end{array}$ & $\begin{array}{l}1.9 \\
2.6 \\
2.3\end{array}$ & $\begin{array}{l}38 \\
26 \\
14\end{array}$ & $\begin{array}{r}770 \\
1,540 \\
2,464\end{array}$ & $\begin{array}{l}316 \\
470 \\
431\end{array}$ & $\begin{array}{l}41 \\
31 \\
17\end{array}$ \\
\hline
\end{tabular}

Table II Effect of infusion rate of the mean water and sodium absorption from the human colon

\begin{tabular}{|c|c|c|c|c|c|}
\hline \multirow{2}{*}{\multicolumn{2}{|c|}{$\begin{array}{c}\text { Subject Infusion } \\
\text { Rate } \\
(\mathrm{ml} / \mathrm{min})\end{array}$}} & \multirow{2}{*}{$\begin{array}{l}\text { Mean } \\
\text { Transit } \\
\text { Time of } \\
\text { PSP (min) }\end{array}$} & \multicolumn{3}{|c|}{$\begin{array}{l}\text { Percentage of Perfusate Absorbed } \\
\text { per Minute of Colonic Transit }\end{array}$} \\
\hline & & & Sodium & Chloride & Water \\
\hline 1 & $\begin{array}{r}5 \\
10 \\
16\end{array}$ & $\begin{array}{l}37 \cdot 5 \\
41 \cdot 8 \\
16 \cdot 9\end{array}$ & $\begin{array}{l}1.09 \\
0.60 \\
1 \cdot 15\end{array}$ & $\begin{array}{l}1.37 \\
0.79 \\
1.60\end{array}$ & $\begin{array}{l}0.92 \\
0.43 \\
0.92\end{array}$ \\
\hline 2 & $\begin{array}{r}5 \\
10 \\
16\end{array}$ & $\begin{array}{l}38 \cdot 4 \\
21 \cdot 1 \\
26 \cdot 8\end{array}$ & $\begin{array}{l}1.28 \\
1.98 \\
0.84\end{array}$ & $\begin{array}{l}1 \cdot 56 \\
2 \cdot 22 \\
1 \cdot 14\end{array}$ & $\begin{array}{l}1.13 \\
1.64 \\
0.59\end{array}$ \\
\hline 3 & $\begin{array}{r}5 \\
10 \\
16\end{array}$ & $\begin{array}{l}32 \cdot 8 \\
30 \cdot 2 \\
14 \cdot 1\end{array}$ & $\begin{array}{l}1 \cdot 17 \\
0.90 \\
0.84\end{array}$ & $\begin{array}{l}1 \cdot 51 \\
1 \cdot 19 \\
1 \cdot 34\end{array}$ & $\begin{array}{l}1 \cdot 11 \\
0.80 \\
0.75\end{array}$ \\
\hline 4 & $\begin{array}{r}5 \\
10 \\
16\end{array}$ & $\begin{array}{l}60 \cdot 1 \\
46 \cdot 9 \\
31 \cdot 6\end{array}$ & $\begin{array}{l}0.70 \\
0.65 \\
0.52\end{array}$ & $\begin{array}{l}0.96 \\
0.94 \\
0.84\end{array}$ & $\begin{array}{l}0.62 \\
0.55 \\
0.43\end{array}$ \\
\hline
\end{tabular}

Table III Absorption of sodium, chloride, and water from the human colon perfused at different rates in four patients

of colonic transit was approximately $1 \%$ at all speeds and for each subject (Table III).

\section{Discussion}

These results demonstrate that the rectum does not absorb electrolytes and water from physiological solutions placed in the lumen. In this regard the rectum differs markedly from the remainder of the large intestine, which transports sodium and chloride from the lumen against large gradients of concentration (Devroede and Phillips, 1969b). The rectal mucosa was not totally impermeable to electrolytes; small amounts of ${ }^{24} \mathrm{Na}$ disappeared from test solutions, indicating minimal diffusion of the label from the lumen, presumably into the circulation. However, net absorption of electrolytes in water was negligible with reference to PEG, which has been validated (Shields, Harris, and Davies, 1968; Devroede and Phillips, 1969a) as a suitable non-absorbable marker in the human large intestine.

The lack of rectal absorption was most evident when a single injection of test solution was sampled for 90 minutes. However, in preliminary studies we were unable to occlude the sigmoid colon completely, even with a large balloon, as others have also found (Levitan et al, 1963). When volunteers were positioned on the right side, solutions were probably confined to the rectum since PEG was not recovered by suction proximal to the balloon. Moreover, fluid did not leak from above the balloon into the rectum, as PEG dilution did not occur. Despite the reassurance of these findings, we felt an alternative method was necessary. Studies utilizing intraluminal perfusion, with a 'mixing segment' (Cooper, Levitan, Fordtran, and Ingelfinger, 1966), confirmed the lack of absorption from the rectum even when the distal site of sampling was occluded 
to increase the duration of contact between perfusates and the mucosa. By contrast, the remainder of the large intestine absorbed electrolytes and water effectively from identical solutions. Absorption from the colon varied with transit time of solutions and at approximately $1 \%$ per minute of contact between perfusates and the absorptive surface. A similar rate of absorption by the rectal mucosa would have produced marked changes in PEG and electrolyte concentrations especially in the 'bolus studies' when test solutions were in the rectum for periods of 15 to 90 minutes.

Previous studies have shown that sulphisoxazole and radioiodine are absorbed from the human rectum (Levitan et al, 1963) and also that tritiated water diffuses from the rectosigmoid into venous blood (Levitan and Brudno, 1967). However, comparisons between absorption from the rectum and from the other areas of the colon were not made and quantitative interpretation of these studies is limited because spread of test solutions into the descending colon cannot be excluded. Other methods have employed surgically isolated segments of large intestine. Water and electrolytes were not absorbed from an isolated loop of the rectosigmoid junction (Annis and Alexander, 1952) or rectum (Duthie and Atwell, 1963), in contrast to their absorption from similar loops of the proximal colon (Duthie and Atwell, 1963).

The localization of colonic function demonstrated in our studies is relevant to the physiology of colonic absorption and the effects of segmental disease or resection of the large intestine. The results complement the demonstration of a gradient of decreasing permeability to labelled sodium $\left({ }^{24} \mathrm{Na}\right)$ and water (deuterium oxide) across the mucosa of the caecum, transverse colon, descending colon, and rectum (Devroede, 1968). The caecum is more permeable to sodium and water than other regions of the large intestine (Devroede, 1968) and greater amounts of saline perfusates are absorbed in the proximal colon (Levitan et al, 1962), implying that electrolytes and water are reabsorbed predominantly in this region. Thus, disease or resection of the proximal colon should compromise colonic function to a greater degree than more distal pathology. Conversely, in idiopathic proctitis the observation that diarrhoea is not a universal symptom (Lennard-Jones, Langman, and Jones, 1962; Bargen, 1969) is explicable if the rectum normally absorbs negligible amounts of electrolytes and water. Minimal disturbances of bowel habit may accompany colectomy and ileoproctostomy, particularly when performed for familial polyposis (Teicher and Abrahams, 1956). Under these circumstances, the production of formed stools suggests an alteration of normal rectal function or an augmentation of water reabsorption by the terminal ileum.

\section{References}

Annis, D., and Alexander, M. K. (1952). Differential atsorption of electrolytes from the large bowel in relation to ureterosigmoid anastomosis. Lancet, 2, 603-606.

Bargen, J. A. (1969). Chronic Ulcerative Colitis: A Lifelong Study. Thomas, Springfield, Illinois.

Cooper, H., Levitan, R., Fordtran, J. S., and Ingelfinger, F. J. (1966). A method for studying absorption of water and solute from the human small intestine. Gastroenterology, 50, 1-7.

Devroede, G. J. (1968). Transport of Water and Electrolytes in the Human Large Intestine. Thesis, Mayo Graduate School of Medicine (University of Minnesota), Rochester, Minn.

Devroede, G. J., and Phillips, S. F. (1969a). Studies of the perfusion technique for colonic absorption. Gastroenterology, 56, 92-100.

Devroede, G. J., and Phillips, S. F. (1969b). Conservation of sodium, chloride, and water by the human colon. Gastroenterology, 56, 101-109.

Duthie, H. L., and Atwell, J. D. (1963). The absorption of water, sodium, and potassium in the large intestine with particula reference to the effects of villous papillomas. Gut, 4, 373-377.

Hyden, S. (1956). A curbidimetric method for the determination of higher polyethylene glycols in biological materials. $K$. LantbrHögsk. Annlr., 22, 139-145.

Kanaghinis, T., Lubran, M., and Coghill, N. F. (1963). The composition of ileostomy fluid. Gut, 4, 322-338.

Lennard-Jones, J. E., Langman, M. J. S., and Jones, F. Avery (1962). Faecal stasis in proctocolitis. Gut, 3, 301-305.

Levitan, R., Bikerman, V., Burrows, B. A., and Ingelfinger, F. J. (1963). Rectosigmoidal absorption of phenolsulfonphthalein (PSP), sulfisoxazole diethanolamine (Gantrisin), and radioiodine $\left(\mathbf{I}^{131}\right)$ in normal subjects and patients with idiopathic ulcerative colitis. J. Lab. clin. Med., 62, 639-645.

Levitan, R., and Brudno, S. (1967). Permeability of the rectosigmoid mucosa to tritiated water in normal subjects and in patients with mild idiopathic ulcerative colitis. Gut, 8 , 15-19.

Levitan, R., Fordtran, J. S., Burrows, B. A., and Ingelfinger, F. J. (1962). Water and salt absorption in the human colon. J. clin. Invest., 41, 1754-1759.

Phillips, S. F. (1969). Absorption and secretion by the colon. Gastroenterology, 56, 966-971.

Shields, R., Harris, J., and Davies, M. W. (1968). Suitability of polyethylene glycol as a dilution indicator in the human colon. Gastroenterology, 54, 331-333.

Teicher, I., and Abrahams, J. I. (1956). The treatment of selected cases of multiple polyps, familial polyposis, and diverticular disease of the colon by subtotal colectomy and ileoproctostomy. Surg. Gynec. Obstet., 103, 136-146. 